\title{
EVALUATING AND PREVENTING POLLUTION FROM NAVIGATION IN THE BLACK SEA COASTAL AREAS IN THE CONTEXT OF CLIMATE CHANGE
}

\author{
Alina GÎRLEANU*, Eugen RUSU \\ "Dunărea de Jos" University of Galati, Faculty of Engineering, \\ Mechanical Engineering Department, Galati, Romania \\ email: alina.girleanu@damen.com
}

\begin{abstract}
Nowadays, studying climate change of the coastal zones is of utmost importance, due to the fact that global warming endangers in particular sea coast regions. As a matter of fact, the scientist and one of the founders of physical climatology, Budiko, in 1972, stated that first of all, due to the rising use of fossil fuels, a significant rise in the air temperature will occur, then extensive flooding of coastal areas will be caused by this appearance of climate change, ecomigration will follow, along with massive economical loss, generating a chain-reaction process.

Taking the Black Sea into consideration, it is more than clear that pollution has reached record levels during the last decades. Hydrocarbons, which are naturally-occurring compounds that form the basis of coal, natural gas and crude oil, are responsible for more than $80 \%$ of energy consumption, but unfortunately, it is now common knowledge that using them as the primary source of energy, it contributes to increasing climate changes.

Furthermore, marine accidents, such as collisions and explosions, contribute significantly to pollution, with consequences on coastal ecosystems and onshore human activities. This paper aims to lay emphasis on the impact that navigation, alongside with climate change has on the marine environment and analyse the available data regarding the marine accidents using satellite monitoring in order to control and prevent disasters that may occur while operating ships at sea.
\end{abstract}

Keywords: Black Sea, climate change, oil pollution, navigation, coastal zones, satellite monitoring

\section{INTRODUCTION}

Due to the fact that the Black Sea is a transit area for gas and oil resources from the Caspian Sea and Russia (where the petroleum industry is one of the largest in the world, and it is by far the world's largest natural gas exporter), the Black Sea is subjected to high navigation traffic; and despite the fact that it is an enclosed sea, the wave-wind conditions are comparable with those from the ocean and the risk of accidents, therefore the risk of pollution, becomes really high in such situations [14]. The early-2020 oil price war and the COVID-19 pandemic drove oil prices to record lows as of late April, 2020. As a result, oil markets have become extremely volatile, and global production has changed significantly. However, oil pollution remains an ongoing threat along major shipping routes and coastal areas around industrial factories, ports (Odessa, Samsun, Constanta, Varna, Sochi), river mouths (the second longest river in Europe flows into it - the Danube river). The main entrance in the seventh Pan European navigation corridor the mouths of the Danube River - where tangled wave-current interactions increase in a significant way the navigation risks $[5,9,10]$. Moreover, several Black Sea ports in Russia and Georgia are terminals for oil and gas pipelines from the Caspian Sea, but even a greater risk comes along with these activities, such as random pollution and oil spills.

About 50000 vessels transit the Bosphorus and Dardanelles straits each year, and at least 10000 oil f Doctoral Schools of "Dunărea de Jos" University of Galati (SCDS-UDJG), 13th and 14th of June 2019, Galati, Romania. 


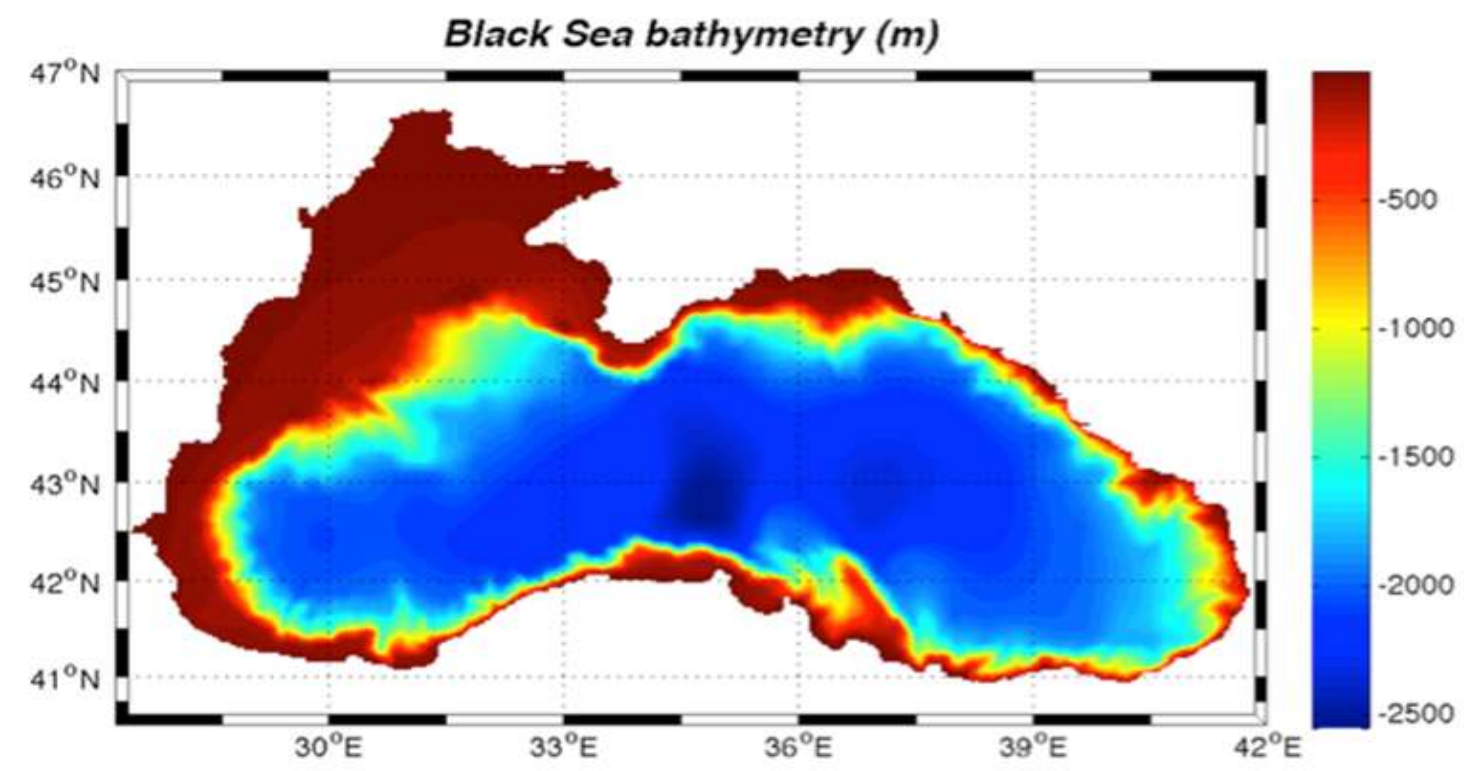

Fig. 1. The bathymetric map of the Black Sea [17]

tankers, making this area one of the world's busiest maritime gateways [6]. Among the characteristics that make the Black Sea unique, some are worth mentioning. Over $85 \%$ of its deeper water volume consists of anaerobic (oxygen-free) water (at a depth greater that 200 metres, there is a permanent hydrogen sulphide zone devoid of life) and, as a result, the diversity of organisms is quite limited. Major changes to the ecosystem, judging by what has been stated in the Black Sea Environmental Programme - Transboundary Diagnostic Analysis (TDA) in 2007 regarding the causes of the decline in fish commercialisation during the past 40 years, obviously represents an indicative of its liability to the anthropogenic effects. Another important source of pollution is through the ballast water that it is vital for the safe operation of ships. It provides stability and manoeuvrability during a voyage or during the operations of loading/unloading [5]. When ballast water is loaded, millions of micro-organisms are introduced into the ballast tanks of vessels. Many of them are able to survive and when unloaded, they are released into new environments, reproducing and becoming possible invasive species. Consequently,

This leads to the extinction of native species, negative effects on onshore human activities, and health issues for those who use the local water and so on and so forth. In order to reduce these extremely harmful effects, the International Maritime Organization (IMO) adopted in 2004 a convention in order to control and manage ships ballast and sediments [7].

\section{CASES OF OIL POLLUTION IN THE BLACK SEA}

The Black Sea is an inland sea, located deeply inside the continent. In the south-west, it is connected via the Bosphorus Strait with the Sea of Marmara.
The Kerch Strait connects the Black Sea with Sea of Azov. The crossroads of trade civilisation and legends - the Bosphorus Strait - has a length of 31 $\mathrm{km}$ at a width that varies between 730 and $3300 \mathrm{~m}$, and the depth of the navigation channel is in between 20 and the maximum depth $110 \mathrm{~m}$ [8]. The three main structures consist of the shelf (occupies almost $25 \%$ of the total area of the seafloor and is restricted to sea-depths of $150-200 \mathrm{~m}$ ), the continental slope and the deep-water basin. The bathymetric map of the Black Sea is revealed in Figure 1.

The Black Sea is surrounded by six countries with developed industry in the coastal zones. There are numerous industrial ports with oil terminals and Figure 2 presents the fierce marine traffic, which is a key factor to the increasing number of negative effects on the environment [17]. Taking into account the data provided with the help of satellite monitoring of European seas [18, 19], apart from oil pollution coming from vessel spills, there are also films revealing intense phytoplankton bloom, and even natural hydrocarbon outflows (methane seepages) [20]. Studies and research conducted on the south-eastern continental slope have shown that there is methane coexisting simultaneously as gas hydrates and in free form. This is due to the existence of oil traces in seabed gas hydrates. [20, 21]. According to observations, studies and research, the most probable cause of these seepages is the distinctive geological structure of the south-eastern margin of the Black Sea [22].

As stated by statistics, the north and west Iberian coasts of the Atlantic Ocean are one of the areas with the highest risk of oil spillages in the world. One tragic example is the accident that happened in Spain, of the oil carrier Prestige of Vigo, in the year 2002 that had an overwhelming ecological and economic impact. On the same hand, the risk of oil pollution in the Black Sea (which has become a 
transit route of major maritime traffic) is alarmingly high due to the fact that the wave climate is sometimes identified with sudden storms. The most recent accident happened on 22 January, 2019, when Maestro and Candy LPG tanker vessels caught fire, during a ship-to-ship transfer operation, which is a loading method that is sometimes used to circumvent port access restrictions or sanctions; the outcome resulted in 14 crew members confirmed dead and another 5 missing and presumed dead in the Kerch Strait [13]. Another serious and debated example of dangerous oil spillage took place on November, 2007. With extremely severe weather conditions, such as winds exceeding $30 \mathrm{~m} / \mathrm{s}$ causing 4 meter-high waves, an oil spill took place in the Kerch Strait [12]. No less than 13 vessels were sunk or damaged, and, as reported by the Ukrainian Ministry of Transport, the quantity of "on-the-spot spillage" was 25 tonnes of diesel marine oil, 2.3 tonnes of oil lubricants, and more than 1300 tonnes of heavy oil [12].

\section{STATE-OF-THE-ART METHODS TO DETECT OIL SPILLS}

A wide-range of observations over the past 30 years demonstrate that the number of illegal discharges into the Black Sea has increased, posing serious threats to the marine environment $[2,3]$. The examples and the data collected made it possible to draw some conclusions and to lay emphasis on the negative influence that pollution has on marine environment. When an oil spill takes place, it is likely to spread over the surface of the sea water, resulting in a deadly impact on marine organisms and human life. It goes without saying that prevention is better than cure, thus, by providing pollution detection, the CleanSeaNet monitoring service supports coastal states' actions to detect and then combat deliberate or accidental pollution in the marine environment. CleanSeaNet is the European satellite-based oil spill monitoring and vessel detection service that was developed and operated by EMSA (European Maritime Safety Agency) [11]. The main reasons why we have to keep a close eye on spills from vessels, offshore platforms and oil pipelines is because they can severely pollute marine and coastal habitats, causing damages to the environment.

CleanSeaNet monitoring is possible through the use of Synthetic Aperture Radar (SAR) and optical images, which are the results of electromagnetic pulses generated by radar, that are reflected by the ocean surface [11]. Through measuring the roughness of the sea surface, resulting images display features which stand out from the background. Bright spots are represented by vessels, while oil spills appear as dark irregular shapes. What needs to be outlined is the fact that images can be acquired regardless of weather conditions and the time-frame. The optical sensors include visible, near infrared and short-wave infrared wavelengths, releasing pictures that are similar to the way in which human eye sees the surroundings [11].

One example was reported on 22 August, 2018, on the Bulgarian coast, in the Black Sea, near the beach of Sozopol, when a SAR image from CleanSeaNet service detected a possible oil spill above the location of a well-known wreck, the Mopang, which has sunk in 1921 [14]. The volume of fuel oil discharged was estimated around the value of $70 \mathrm{~m}^{3}$, of around $650 \mathrm{~m}^{3}$ on board. The Bulgarian Maritime Administration contacted EMSA to request emergency assistance and to undertake an underwater operation in order to pump out the remaining fuel. Moreover, additional satellite images were ordered to monitor the situation and assess the effectiveness of the protective measures. In less than two months, the cleaning operations came to an end, without any other incident. The major two different types of

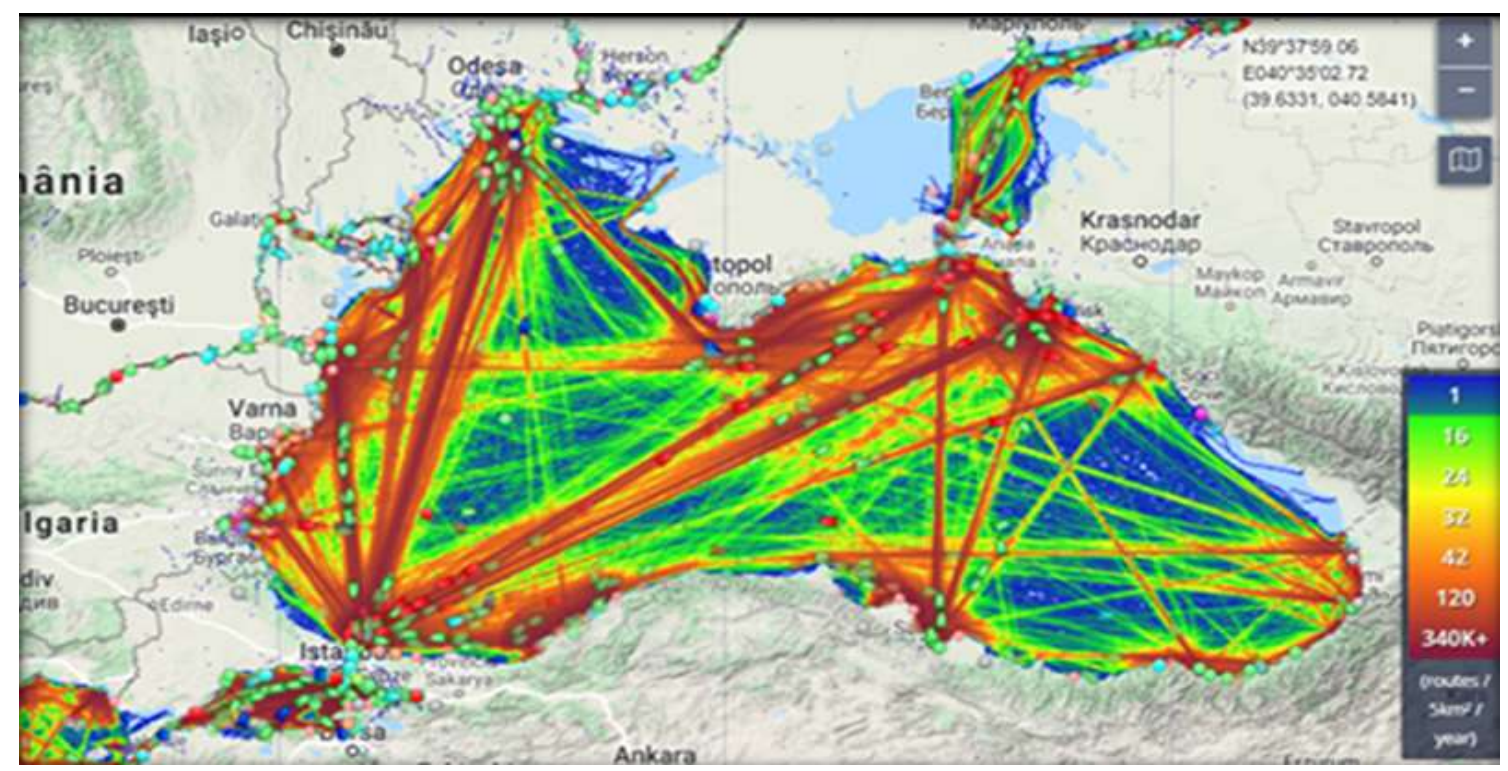

Fig. 2. The Black Sea Shipping traffic density map 
activity undertaken by CleanSeaNet consists of routine daily tasks, which means that images are planned in advance all year round, with the purpose of detecting vessels discharging, in an illegal way, substances like oil. Secondly, pictures can also be acquired at short notice following an incident at sea, to check whether there has been a spill and, if so, to track the spread of oil subsequently [11].

EMSA provided expertise to the European Commission and member states throughout 2019 to help them tackle a variety of issues related to the prevention of pollution caused by vessels, confirming the Agency's strong commitment to sustainability and greener navigation. Among the issues, a few worth mentioning are [11]:

- Supporting an analysis of the $\mathrm{CO} 2$ emissions data recorded in the THETIS-MRV system, a report which is expected to be made public during mid2020, enabling further assessments of CO2 emissions and the energy efficiency measures in place in the EU.

- Contributing to the adoption of the revised Port Reception Facilities Directive and monitoring the implementation of the Ship-Source Pollution Directive.

- Holding technical workshops in order to raise awareness of the upcoming $0.5 \%$ limit on the sulphur content of marine fuels effective from 2020.
- Support to the European Commission's proposal to ban the use of cybutryne starting from October 2021, as well as to ban ships using such coating from October 2026.

- Development of Guidance for best practices on sampling as foreseen by the Ballast Water Convention.

\section{DISCUSSION ON THE DATA ANALYSED DURING THREE YEARS OF SATELLITE OBSERVATIONS (2009-2011)}

The major data source consisted of highresolution radar imagery data obtained by synthetic aperture radars onboard Envisat satellite (until April, 2012) and onboard Sentinel-1 (starting from October, 2014) $[15,16]$. Meteorological data required was provided by coastal stations. The SAR images were acquired via internet from the three European stations ESRIN, MATERA and KIRUNA in near-real time mode in the framework of scientific projects of ESA [23]. The description of an oil slick on the sea surface includes geographic coordinates of the slick, the polluted area, the presence of a vessel as a possible source of pollution [24].

Figure 3(a) reveals a part of a radar image taken in the Kerch Strait under low wind and low surface waves conditions, while in figure 3(b) it is presented the central part of the Black Sea under moderate wind conditions and more intense surface waves.

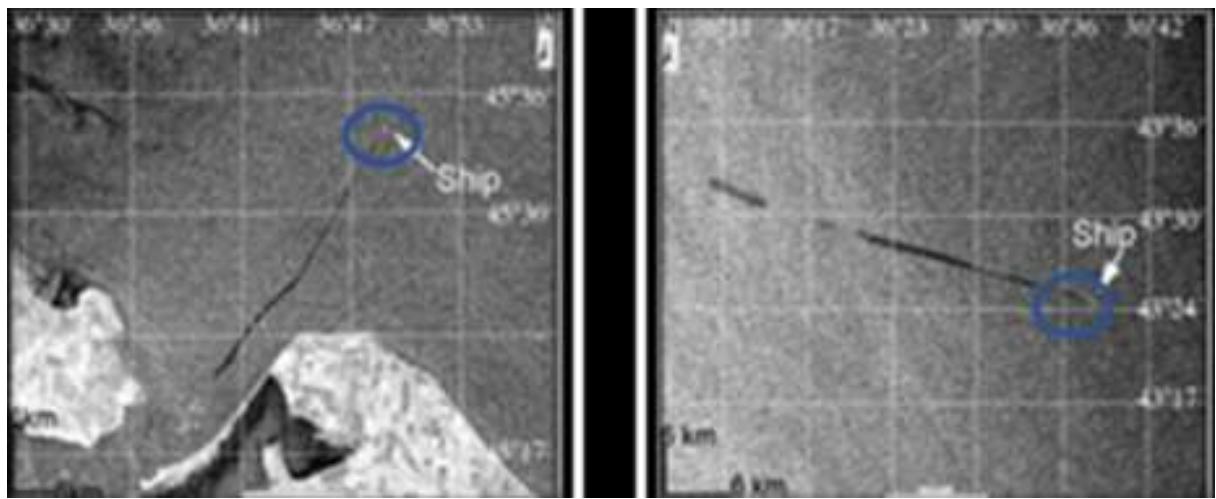

Fig. 3. (a) Fresh oil spills from moving vessel, ASAR Envisat, 10 June 2008, 19:18 UTC [24]; (b) ASAR Envisat, 10 June 2008, 19:18 UTC [24]

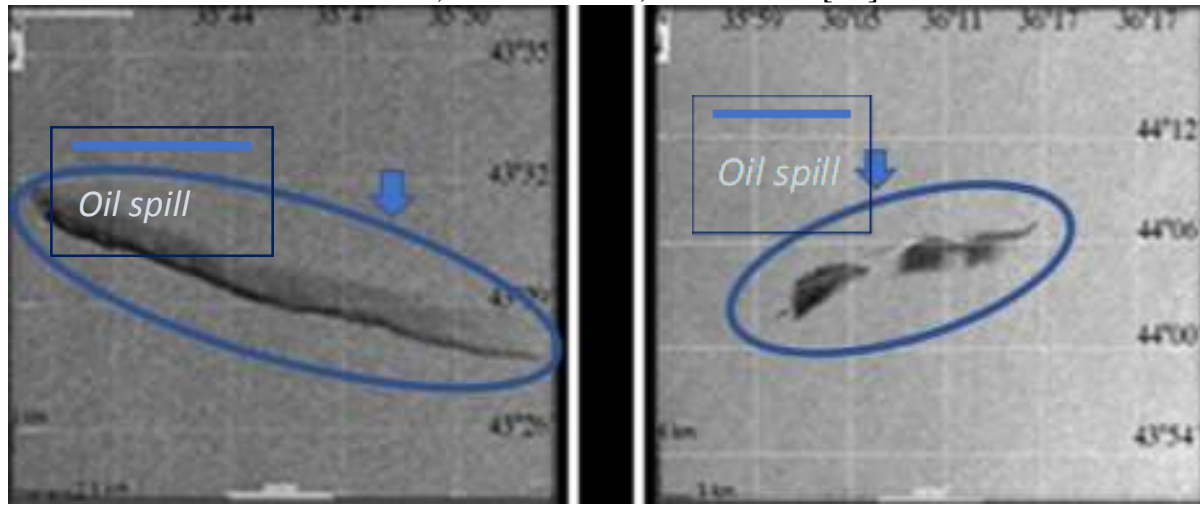

Fig. 4. Weathered oil spill of "comb-like" structure seen in SAR imagery; (a) SAR Sentinel-1, 25 September 2015; (b) ASAR Envisat, 12 June 2010 
The bright point indicates the vessel moving. Multiple spills from moving vessels are caused by oil tankers washing their tanks in open sea.

Figure 4 presents a "comb-like" structure that is solely characteristic of oil spill pollution. The nearsurface wind can induce dynamic processes in the upper layer of the sea, leading to the appearance of divergence and convergence zones on the sea surface, and the concentrated oil spill in the distant zone, becoming the key factor affecting the detection of oil pollution on the sea surface through radar imagery.
Figure 5 reveals over 600 cases of pollution caused by oil discharges during three years of satellite observations (2009-2011). The number of cases decreased each and every year (286 in 2009, 253 in 2010 and 247 in 2011) The spillages are concentrated along the main shipping routes such as Istanbul-Odessa, Istanbul-Novorossiysk and IstanbulTuapse [24]. Apart from these ones, numerous others are observed near the largest ports of Romania, Bulgaria and Ukraine

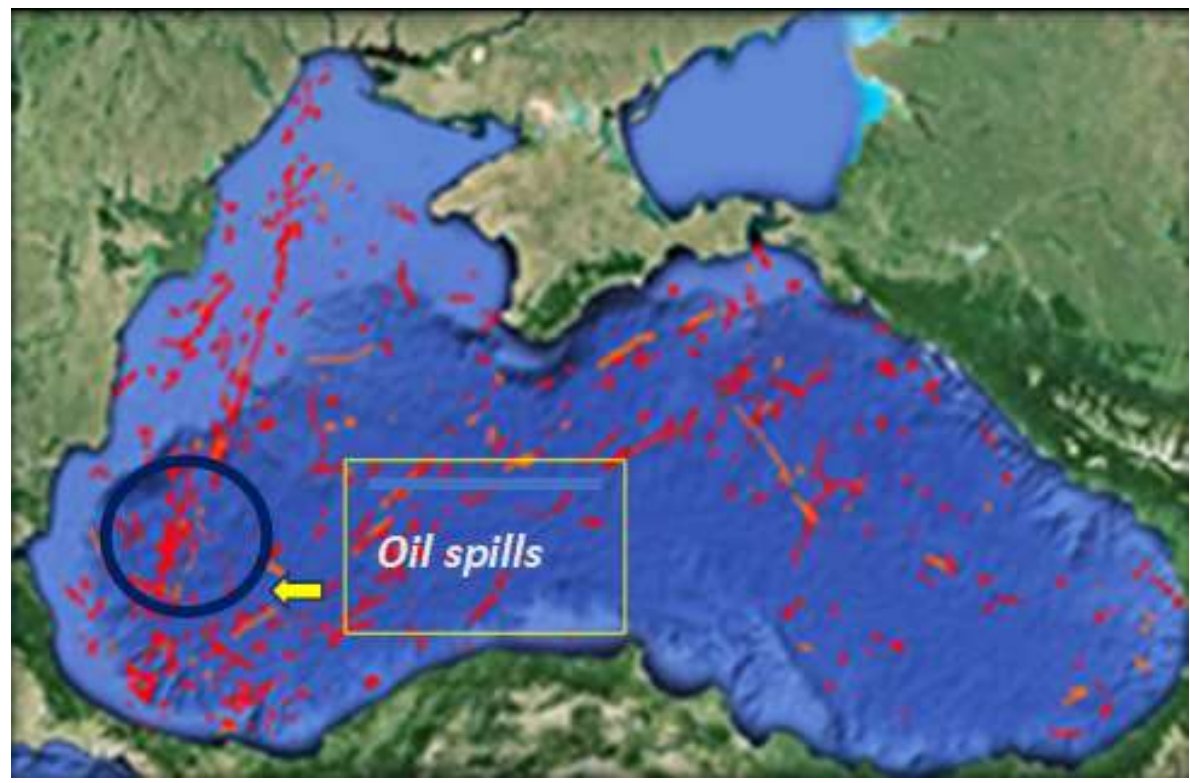

Fig. 5. Map of oil spills in the Black Sea during 2009-2011 [24]

\section{CONCLUSIONS}

Major accidents involving dangerous substances pose a significant threat to human life and the surrounding environment. In order to minimise the associated risks, measures are necessary to prevent major accidents and to ensure appropriate preparedness and response.

Taking everything into account, the studies and research conducted throughout the years have demonstrated an actual demand for satellite monitoring of surface pollution in an inland sea, as the Black Sea, in order to reveal the source, evaluate the scale and predict the spreading of oil pollution into the marine environment, where most of the accidents with significant consequences are due to shipping. Currently, the further development of high resolution satellite radar monitoring systems is of great importance for the modern operational oceanography.

By and large, as it has been stated briefly at the beginning of the present paper, it should definitely be taken into consideration the fact that the Black Sea has the largest meromictic basin in the world [4] and in the event of an unfortunate case, the release of the hydrogen sulphide clouds could endanger the human lives and nearshore activities, especially for those who have been established on the Black Sea coast.

\section{ACKNOWLEDGEMENTS}

This work was supported by the project "Excellence, performance and competitiveness in the Research, Development and Innovation activities at "Dunarea de Jos" University of Galati", acronym "EXPERT", financed by the Romanian Ministry of Research and Innovation in the framework of Programme 1-Development of the national research and development system, Sub-programme 1.2Institutional Performance - Projects for financing excellence in Research, Development and Innovation, Contract no. 14PFE/17.10.2018.

\section{REFERENCES}

[1] Rusu L., Bernardino M. (2012) Assessment of wind and wave simulations for enclosed sea using satellite data, in Maritime Engineering and Technology, DOI: 10.1201/b12726-66.

[2] Gasparotti C., Rusu E. (2012) Methods for the Risk Assessment in Maritime Transportation in the 
Black Sea Basin, Journal of environmental protection and ecology, 13(3A), pp. 1751-1759.

[3] Rusu L. (2010) Application of Numerical Models to Evaluate Oil Spills Propagation in the Coastal Environment of the Black Sea, Journal of Environmental Engineering and Landscape Management, 18(4), pp. 288-295, https://doi.org/10.3846/jeelm.2010.33

[4] Onea F., Rusu E. (2014) Evaluation of the Wind Energy in the North-West of The Black Sea, International Journal of Green Energy, 11(5), pp. 465487, https://doi.org/10.1080/15435075.2013.773513.

[5] Gasparotti C., Domnisoru L., Rusu, E. (2014) Scenarios for the navigation routes in the Black Sea considering the seakeeping safety criteria, $14^{\text {th }}$ International Multidisciplinary Scientific GeoConference SGEm.

[6] *** Bosphorus: the crossroads of trade, civilisation and legends, ttps://www.trtworld.com/turkey/bosphorus-thecrossroads-of-trade-civilisation-and-legends-20594 (accessed on 29.05.2020)

[7] *** Ballast water management - the control of harmful invasive species, International Maritime Organisation, (accessed on 28.05.2020), http://www.imo.org/en/MediaCentre/HotTopics/BW $\mathrm{M} /$ Pages/default.aspx

[8] *** 6 Bosphorus Strait Facts You Must Know, (acceseed on 29.05.2020), https://www.marineinsight.com/know-more/6bosphorus-strait-facts-you-must-know/

[9] Rusu E. (2010) Modeling of Wave-current Interactions at the Danube's Mouths, Journal of Marine Science and Technology, 15(2), pp. 143-159, DOI: 10.1007/s00773-009-0078-x.

[10] Ivan A., Gasparotti C., Rusu E. (2012) Influence of the Interactions between Waves and Currents on the Navigation at the Entrance of the Danube Delta, Journal of Environmental Protection and Ecology, 13(3A), pp. 1673-1682.

[11] *** http://emsa.eurpa.eu/EMSA Facts and Figures 2019 (accessed on 30.05.2020)

[12] Korshenko A., Ilyin Y., Velikova V. (2011) Oil spill accident in the Kerch Strait in November 2007, Black Sea commission publications. Moscow, Nauka.
[13] *** LPG Tanker explosion Kills 14 Crew Near Kerch Strait (2019), https://safetyatsea.net/news/2019/lpg-tanker-

explosion-kills-14-crew-near-kerch-strait/ (accessed on 29.05.2020)

[14] ISCO (International Spill Control Organization), ISSUE 652. 2018

[15] *** https://earth.esa.int/web/eoportal/satellitemissions/c-missions/copernicus-sentinel-1 (accessed on 31.05 .2020 )

[16] $* * *$ ENVISAT Satellite mission https://directory.eoportal.org/web/eoportal/satellitemissions/e/envisat (accessed on 31.05.2020)

[17] $* * *$ Marine Traffic, http://marinetraffic.com (accessed on 29.05.2020).

[18] Mityagina M.I., Lavrova, O.Y., Bochorova, T.Y. (2015) Satellite monitoring of oil pollution of the sea surface, International Geoscience and Remote Sensing Symposium (IGARSS), DOI: 10.1109/IGARSS.2015.7326265.

[19] Mityagina M.I., Lavrova O.Y. (2013) Satellite monitoring of oil slicks on the Black Sea surface. Izvestiya, Atmospheric and Oceanic Physics, 49, pp. 897-912.

[20] Korber J.H., Sahling H., Pape T., Ferreire K.S., McDonald I., Bohrmann G. (2014) Natural oil seepage at Kobuleti Ridge, eastern Black Sea, Marine and Petroleum Geology, 50, pp. 68-82. doi:10.1016/j.marpetgeo.2013.11.007.

[21] Reitz A., Pape T., Haeckel M. (2011) Sources of fluids and gases expelled at cold seeps offshore Georgia, Eastern Black Sea, Geochimica et Cosmochimica Acta, $\mathbf{7 5 ( 1 1 ) ,}$ DOI: 10.1016/j.gca.2011.03.018

[22] Klaucke I., Sahling H., Bork, D., Weinrebe W., Bohrmann, G. (2005) Mapping deep-water gas emissions with sidescan sonar EOS, Transactions American Geophysical Union, 86(38), pp. 341-346. doi:10.1029/2005EO380002

[23] Lavrova O.Y., Kostianoy, A.G.; Lebedev, S.A.; Mityagina, M.I.; Ginzburg, A.I.; Sheremet, N.A. (2011) Complex satellite monitoring of the Russian Seas; IKI RAN: Moscow, Russia.

[24] Mityagina M.I., Lavrova, O.Y. (2016) Satellite survey of Inner Seas: Oil Pollution in the Black and Caspian Seas; Moscow, Russia. 